\title{
Systematic variation in examples in mathematics teaching
}

\author{
Angelika Kullberg \& Christina Skodras
}

Teachers face many challenging and important decisions when planning their teaching. In discussing the issues, this essay will go into considerable detail. Imagine that you are going to teach subtraction with regrouping to Year 1 pupils. What do you use as your first example? On what basis do you select the example? Which example should you use next? In a lesson study in Japan, a group of teachers spent a considerable amount of time discussing what would be a good example to start with when teaching subtraction with regrouping in Year 1 (Fernandez \& Yoshida 2004). The team of teachers came to the conclusion that some examples showed better than others what they wanted their pupils to learn (strategies for decomposing the subtrahend-the number being subtracted). For example, 12-7 focused on the decomposition of the subtrahend (here 7 ) in a better way. The team argued that 12-9 would not be a good choice since 9 is so close to 10 that the pupils would not use the strategy that the teachers wanted to focus onin other words, the pupils would decompose the number 12 into 10 and 2 to proceed with the calculation instead of decomposing the number 9 into 2 and 7 . One teacher suggested 12-4, but this example was also rejected because 4 was too easy to decompose $(2+2)$ and the team reasoned it would not bring about the intended 
learning outcome. This suggests that the teachers were aware that the examples they choose are important for what is made salient for learners.

Several studies indicate that what examples are chosen and how they are sequenced are of decisive importance for pupils' learning (for example, Kullberg \& Runesson 2015; Rowland et al. 2003; Watson \& Mason 2006). A study of novice teachers' selection of examples found that examples were selected randomly (Rowland et al. 2003). In another study of more experienced teachers, they claimed that they had never talked about their use of examples with colleagues: 'All five teachers whom we observed claimed that they had never articulated how to select and generate examples-not throughout their years of preservice and inservice education nor with colleagues or other forms of professional communications' (Zodik \& Zaslavsky 2008, 173). These findings may indicate that teachers are not always aware of the choices they make regarding examples or the implications that these choices may have for pupils' learning. Furthermore, Kullberg and Runesson (2015) found that teachers used single examples or only a few examples to illustrate a procedure or mathematical principle. Dienes (1963) argues that single examples are insufficient to generalise from, since several examples are needed to get a sense of a concept.

We would argue that teachers need strategies and tools that can help them plan what examples to use or to decide how to exemplify something in the heat of the moment. The aim of this essay is to illustrate how teachers used systematic variation in and between examples. Two studies, one about multiplicative structure in Year 4 (Skodras 2015), and one about multiplication and division with numbers between o and 1 in Year 7 (Kullberg et al. 2014) are used to show how variation highlights the critical aspects of mathematical topics. In both studies, variation theory (Marton 2015; Marton \& Booth 1997) was used in the analysis of the lessons. 


\section{Variation theory}

Variation theory is the theoretical framework used in the two studies on which this essay is based. The theory emanates from more than thirty years of research in the phenomenographic research tradition (Marton 1981) and is based on the idea that the experience of variation is a prerequisite for learning (Marton 2015; Marton \& Booth 1997). If everything varies, it is not possible to discern differences, since only what varies against an invariant background is likely to be noticed. According to the variation theory of learning, the learner needs to discern critical aspects of the object of learning. A critical aspect is what the learner needs to discern or distinguish between in order to learn. What those critical aspects might be cannot be known in advance, since it depends on the learners. Variation in regard to critical aspects is essential in order to be able to notice an aspect, and to see similarities and differences in relation to other aspects.

Ideas about the discernment of differences through variation are not new and are discussed by several scholars (Dienes 1960; Gibson \& Gibson 1955). Dewey (1916) in Democracy and Education addressed the question of learning as differentiation. He wrote that the way in which something (for example, a chair) differs from something else with regard to its specific features is of significance for learning. It is not the qualities in themselves that are of greatest importance, but instead how they differ from other qualities. 'We do not really know a chair or have an idea of it by inventorying and enumerating its various isolated qualities, but only by bringing these qualities in connection with something else-the purpose which makes it a chair and not a table: or its difference from the kind of chair we are accustomed to, or the 'period' which it represents, and so on' (168).

For teachers, variation theory can be used to plan and analyse teaching and learning. In Chinese pedagogy, teaching with 'variation' (bianshi) is a well-known practice (Huang et al. 2006) that also emphasises variation in regard to instruction. Sun (2011) identifies three ways that bianshi is used in mathematics teaching: in the first way, 'one problem, multiple solutions', the teacher varies the solutions and allows the pupils to discern differences between them; in 
the second way, 'one problem, multiple changes', the teacher varies conditions and conclusions in the mathematical problem, and in the third way, 'multiple problems, one solution', the teacher varies the presentation of problems that could be solved in the same way. In each category, there is a pattern of variation and invariance.

Previous studies have demonstrated that mathematics examples used in a lesson could be described in terms of patterns of variation and invariance (Bartolini Bussi et al. 2013; Watson \& Mason 2006). When sets of examples are presented (by the teacher or in a textbook), certain things vary while others remain invariant. As Watson and Mason (2006) argue, 'Constructing tasks that use variation and change optimally is a design project in which reflection about learner response leads to further refinement and precision of example choice and sequence' (100).

In this essay, we discuss the use of examples in mathematics teaching by reporting sections of two published studies in which variation was used in sets of examples to accomplish pupil learning. The rationale for selecting these studies was that they show two different ways that variation in examples can benefit pupils in their learning of mathematical strategies (Study 1), and of conceptual understanding (Study 2). We do not report the full analysis presented in these studies, and we do not enlarge on the existing, published analysis. Detailed information about the method and process of analysis are found in the studies (Kullberg et al. 2014; Skodras 2015).

\section{Examples used for mathematics teaching}

According to Rowland (2008), the examples teachers use and what they choose to focus on are important. As already noted, it has been argued that single examples may have little effect on pupil learning (Dienes 1960; Mason \& Pimm 1984). For instance, if a teacher only uses the example $0.3 \times 2$ to show that multipliers between 0 and 1 make a 'smaller' product, this may not be sufficient to understand that all multiplication with numbers between o and 1 makes the product 'smaller'. It might be that the teacher is presenting one single example with the intention of its being an example of a generality. By 
just giving one example, the pupils may not experience the example as an instance of a generality (Mason \& Pimm 1984). Furthermore, examples should be selected in a way that invites pupils to think and reason mathematically (Simon \& Tzur 2004). Several researchers indicate (for example, Watson \& Mason 2002) that it is important 'for pupils to have several examples from which to get a general sense of what is being taught' (378). Teachers should choose 'generic examples' that promote the general aspect and not the specific aspect of the example (Mason \& Pimm 1984). Examples should help pupils to move from the specific to the general by making it possible to see relationships and generalisations (Simon \& Tzur 2004; Watson \& Mason 2002, 2006; Zazkis \& Chernoff 2008), and the teacher needs to help pupils not just to 'learn' the example, but to see the generality in sets of examples (Mason \& Pimm 1984). One way to discern relationships in and between examples is through systematic variation.

Variation in examples used for mathematics teaching is considered an essential component for pupil learning. Dienes (1960) suggests four principles for mathematics learning, of which two concern variation: the mathematical variability principle, and the perceptual variability principle. Influenced by Wertheimer (1945), Dienes suggested that certain variation is more effective for concept growth.

With the concept of a parallelogram we can vary the shape by varying the angles and the length of the opposite sides; we can vary the position, as long as we keep the opposite sides parallel. Clearly a set of congruent parallelograms placed in the same position would not be a suitable set of experiences for the growth of the concept. We might formulate this by saying that as many variables as possible should vary so as to provide optimum experience in concept growth. (Dienes 1960, 43)

By giving the pupils the opportunity to see parallelograms in several examples, as Dienes suggests, the pupils are offered the chance to identify key mathematical ideas. Dienes highlights that it is not enough to provide several examples of the same type, such as ones 
where all parallelograms are placed in the same position. If pupils only experience the same type of examples, it will not support them in gaining a thorough understanding of the concept. In Dienes's example with the parallelogram, two critical aspects for pupils' experiences of parallelograms are mentioned, shape and position. Sun (2011) argues that looking at 'one-thing-at-a-time' gives fewer opportunities to link the examples to one another than looking at several aspects simultaneously. If the example only focuses on 'onething-at-a-time', the pupils may have greater difficulty in discerning the critical aspects.

\section{Study 1 , teaching multiplicative structure}

Study 1 reports on findings from a BA dissertation which illustrates how variation is used in classroom teaching in enacted sets of examples in multiplication (Skodras 2015). The data was generated from lessons about multiplication taught in Year 4 with fifteen pupils. The study examined how examples in multiplication taken from the teaching material Muffles' Truffles (Cameron \& Fosnot 2007) are constructed and what aspects it was made possible to discern for pupils in the classroom when the teacher used the material. The teacher (the second author) had sixteen years of experience of teaching in elementary school. The pupils, who participated voluntarily and had written consent to participate, had previously experienced multiplication as repeated addition, an additive structure (for example, $4 \times 3=3+3+3+3$ ).

In the study, the teacher uses arrays to illustrate the multiplicative structure for the pupils. The examples used during the lessons are from a teaching guide that is part of the Muffles' Truffles material. This guide differs from many other teaching guides in mathematics since it has 'strings' of examples that are intended for the teacher to use in class. A string is a set of related examples with systematic variation in and between the examples. When teaching one string, the examples are presented one after the other. In that way the pupils have the opportunity to see all the examples separately but can also relate them to the other examples in the string. The study reported 


\begin{tabular}{|c|c|}
\hline $\begin{array}{c}\text { The second } \\
\text { string }\end{array}$ & $\begin{array}{c}\text { The third } \\
\text { string } \\
2 \times 5\end{array}$ \\
$2 \times 5$ \\
$1 \times 5$ & $4 \times 5$ \\
$3 \times 5$ & $4 \times 10$ \\
$5 \times 4$ & $10 \times 4$ \\
$4 \times 5$ & $10 \times 6$ \\
$5 \times 5$ & $6 \times 10$ \\
& $10 \times 12$ \\
& $10 \times 18$ \\
\hline
\end{tabular}

Fig. 3.1.

on an analysis of five lessons with five strings (sets of examples) in multiplication. Skodras (2015) analysed how the examples varied and what was possible for pupils to discern from the examples. In this essay, we present the analysis of the second and the third string, and hence the variation in and between the examples (Fig. 3.1).

In the implementation of the second string, the teacher shows an array to illustrate the multiplication for each example. The first factor in each multiplication represents rows (for example, 2 in $2 \times 5$ ) whereas the second factor in each multiplication represents columns in the array (for example, 5 in $2 \times 5$ ) (Fig. 3.2). The first example $(2 \times 5)$ in both of these strings is familiar to the pupils as they have previously worked with a ' $2 \times 5$ box equals 10 ' in a context about truffles. The example, $2 \times 5$, was represented by the teacher (Fig. 3.2). A key issue is that the teacher shows the arrays very briefly so that pupils do

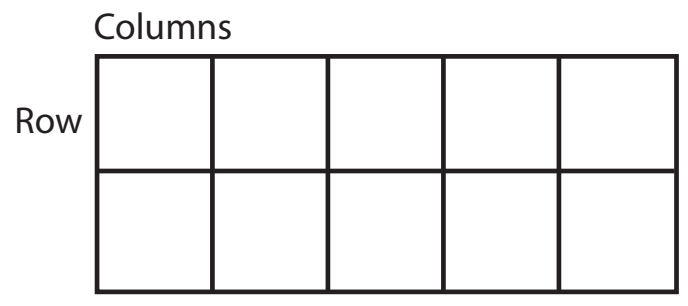

Fig. 3.2. 
not have time to count each square in the array. In the third string, the teacher only writes the example on the board and the pupils are supposed to come up with an array of their own.

\section{Lesson 1, the second string}

This string has six examples that are related to one another with a certain variation in order to highlight critical aspects concerning mathematical strategies and structure. This gives the pupils the opportunity to discern some important mathematical ideas such as the distributive law and the commutative law (Fig. 3.3).

The variation of the first factor in the three examples $(2 \times 5,1 \times 5$, and $3 \times 5$ ), and the fact that the examples are presented as a set and not as one example, gives the pupils the chance to compare the examples and look at relationships (for example, Simon \& Tzur 2004; Watson \& Mason 2002). If the teacher just gave the example $3 \times 5$, it is not certain that the pupils would be able to notice that $3 \times 5$ is a combination of $2 \times 5+1 \times 5$ and the distributive law may not come to the fore. The next pair within the set, $5 \times 4$ and $4 \times 5$, varies in another way, by switching the order of the factors 4 and 5 . When the order of the factors is switched, it becomes possible to distinguish a new critical aspect of multiplication, namely the commutative law. The analysis of what the pupils say in their discussion of the examples $5 \times 4$ and $4 \times 5$ shows that the pupils see that $5 \times 4=4 \times 5$, and reflect on the ways the multiplication can be illustrated with an array (two $2 \times 5$ units or two $5 \times 2$ units combined in different ways, horizontally or vertically). This indicates that the examples $5 \times 4$ and $4 \times 5$ in combination with an array invite pupils to think and reason mathematically (Simon \& Tzur 2004). In this part of the lesson, the pupils reason mathematically about what the first and the second factor stand for, and about the relationship between $5 \times 4$ and $5 \times 2+5 \times 2$. Even in this example, where the focus is on the commutative law, the pupils are forced to use the distributive law $(5 \times 4=5 \times 2+5 \times 2$ and $4 \times 5=2 \times 5+2 \times 5)$ to explain how they should illustrate the multiplication using arrays.

Through the systematic variation in the second string, pupils are 


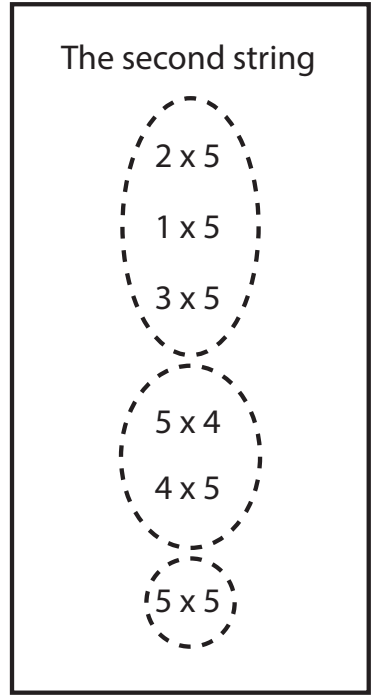

Fig. 3.3.

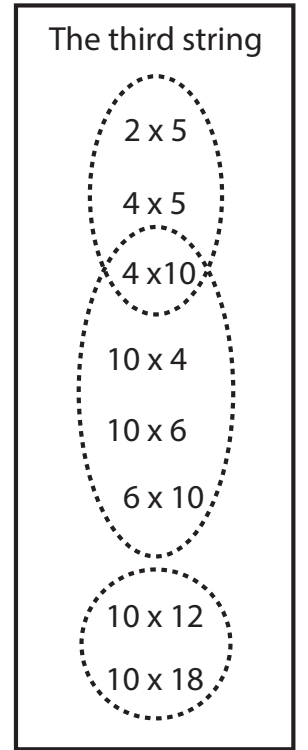

Fig. 3.4.

given an opportunity to solve the last example $(5 \times 5)$ by combining arrays, two $2 \times 5$ arrays and one $1 \times 5$ array arranged vertically. By comparing the different examples in the string, the pupils are able to discern that this last is another example for them to solve with a focus on the distributive law. In this string, the variation in the set of examples highlights different critical aspects concerning mathematical strategies and laws.

\section{Lesson 2, the third string}

In Lesson 2 when the next string is implemented the teacher does not show images of the arrays. Instead, the teacher writes the examples on the whiteboard one at a time. The pupils are prompted to figure out how the multiplication could be illustrated as an array. The string contains eight examples that vary systematically. The examples in this string do not vary in the same way as in the first string.

In the first set (Fig. 3.4), in the examples $2 \times 5=10,4 \times 5=20,4 \times 10=40$ the first or second factor is varied by being doubled. This highlights 


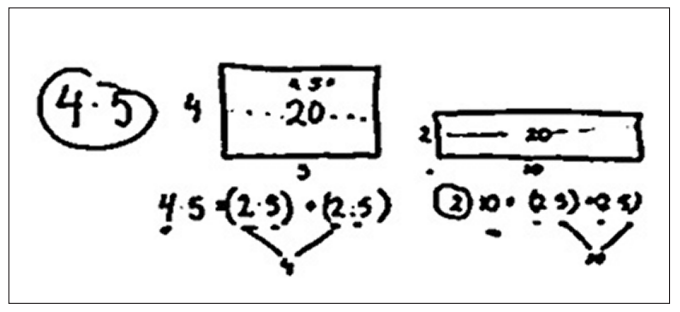

Fig. 3.5.

what happens to the product when one of the factors is doubled. A critical aspect that is highlighted in this set of examples is that it does not matter which factor you double, the product will still be doubled. Furthermore, the examples highlight the difficulties of combining two $2 \times 5$-units into $4 \times 5$ or two $4 \times 5$-units into $4 \times 1$ o. Pupils have different images of $4 \times 5$, which the teacher also highlights in the discussion.

The teacher compares what varied and what is invariant when the pupils combine $2 \times 5$ in two different ways (Fig. 3.5). She asks the pupils why $4 \times 5$ and $2 \times 10$ are equal. Both the pupils and the teacher talk about what varies and what is invariant. In this way, the associative law is introduced (for example, $2 \times(2 \times 5)=(2 \times 2) \times 5)$. However, neither the teacher nor the pupils mention the double/ half aspect (that when one factor is doubled the other halves) $(4 \times 5$ and $2 \times 10)$ in their discussion of $2 \times(2 \times 5)=(2 \times 2) \times 5$.

The examples in the second set $(4 \times 10,10 \times 4$ and $6 \times 10,10 \times 6)$ vary by shifting the position of the factors. It seems that the pupils have discerned the commutative law aspect. One pupil explains that he just 'rotated his paper' 90 degrees and then he had the other array $(6 \times 10$ and $10 \times 6)$. The pupils had previously encountered examples with the same mathematical idea in the first string. We assume that one reason for the construction of the strings is to help the pupils to move from the specific to the general by verbalising relationships and by comparing the examples (for example, Watson \& Mason 2006; Zazkis \& Chernoff 2008) both within and between the strings.

The last set of examples $(10 \times 12$ and $10 \times 18)$ gives the pupil the opportunity to discern the distributive law and a power of $10(10 \times 10)$ 
by splitting $10 \times 12=(10 \times 10)+(10 \times 2)=100+20=120$. The pupils solved the item in three different ways. It is likely that the pupils looked at this example and tried to apply some of the ideas from the previous examples. One of their strategies was doubling $10 \times 6$ to get $10 \times 12$ $(10 \times 6+10 \times 6)$. The second strategy involved repeating the $2 \times 5$-unit 12 times and the third strategy made use of the distributive law, taking the $10 \times 10$ unit and combining it with a $10 \times 2$ unit as follows: $(10 \times 10)+(10 \times 2)$. Hence, we can see that the variation in multiplication of two two-digit numbers gives rise to different strategies. This last set of examples shows how pupils benefited from the string. The string invited the pupils to reflect on and reason about how to solve two two-digit multiplications. The examples allowed the pupils to think and communicate about whether they could represent $10 \times 12$ in these three ways. Is $10 \times 12$ the same as $10 \times 6+10 \times 6$ and the same as $10 \times 10+10 \times 2$ ?

We suggest that the examples used in the lessons had a pivotal role in how the pupils were given opportunities to experience the content. The analysis shows that the way in which the examples were presented allowed the pupils to develop their own mathematical strategies. A relevant factor in the first lesson was the images of multiplication that the teacher showed very briefly. We suggest that these images might have helped the pupils take the step from seeing multiplication as an additive structure to seeing it as a multiplicative structure.

\section{Study 2, teaching multiplication and division with denominators between 0 and 1}

The second study illustrates variation in sets of examples about multiplication and division (Kullberg et al. 2014). The data in the study was generated from a type of theory-driven lesson study (a learning study) about division in Year 7 , in which the teachers wanted their pupils to learn that when the denominator is a number between 0 and 1 , the quotient becomes larger than the numerator. A learning study (Huang et al. 2016; Marton \& Pang 2006) shares many common features with a lesson study (Fernandez \& 
Yoshida 2004; Lewis et al. 2009), in which a team of teachers work in collaboration in a cyclical process to plan, teach, and revise a single lesson. In a learning study, the teachers revise the lesson two or three times, and they use a learning theory (variation theory) as a tool to plan and analyse the lessons. ${ }^{2}$ Four teachers and one researcher worked together for almost a full term. The teachers were experienced mathematics teachers, with about ten years' teaching in lower-secondary school. The teachers collaboratively designed the examples used in the lesson, in contrast to Study 1 in which the examples were designed by the authors of the teaching guide. The aim with a learning study is primarily to identify critical aspects of an object of learning and try to implement the identified critical aspects in the lessons in order to promote pupil learning. During the process of the learning study, the teachers also refined the enactment of sets of examples used in the lessons, and also made changes to the sets. What the teachers pointed out in regard to the examples was mainly what they believed were critical aspects for learning division and multiplication. It is known that pupils often make generalisations from previous experience of operations with whole numbers, for instance pupils may believe that multiplication always 'makes things bigger' whereas division always 'makes things smaller' (Vamvakoussi \& Vosniadou 2004; Verschaffel et al. 2007). The teachers were aware of this, and in the second and third lessons in the cycle it was identified as critical for pupils to see the difference between when division makes a bigger quotient than the numerator and when it does not.

In the learning study, the teachers designed and implemented tasks that they discussed with their pupils. One task (Fig. 3.4) played a major role in the lesson in terms of the amount of time spent on it. Analysis of the pattern of variation and invariance in the set of examples shows that the operations vary in the two columns (multiplication and division), and hence it is possible to notice the difference between the operations. The number 100 is invariant in all examples. We can see that the numbers in the examples in each horizontal row are invariant $(100 \times 20$ and $100 \div 20)$. In each column, the numbers vary, from multiplication and division with larger 


\begin{tabular}{ll}
$100 \times 20=2,000$ & $\frac{100}{20}=5$ \\
$100 \times 4=400$ & $\frac{100}{4}=25$ \\
$100 \times 2=200$ & $\frac{100}{2}=50$ \\
$100 \times 1=100$ & $\frac{100}{1}=100$ \\
$100 \times 0,5=50$ & $\frac{100}{0,5}=200$ \\
$100 \times, 01=10$ & $\frac{100}{0,1}=1,000$ \\
\hline
\end{tabular}

Fig. 3.6.

numbers $(100 \div 20)$, to multiplication and division with smaller numbers $(100 \div 0.5)$. The last two examples in each column have numbers between 0 and 1 ( 0.5 and 0.1 ), as the denominator or one of the factors. The numbers in the whole set were deliberately chosen to make it possible for pupils to experience what happens with the product and the quotient when multiplying or dividing by a number between 0 and 1 .

The examples in the set were designed to draw attention to critical aspects for pupils' learning of why the quotient is sometimes bigger than the numerator (Fig. 3.6). The critical aspects identified by the teachers before the first lesson were ( $i$ ) the relationship between the numerator, denominator, and quotient; (ii) the two forms of division (partition and measurement); (iii) the positioning system for numbers; (iv) differences between multiplication and division; and $(v)$ what a number between $o$ and 1 is. However, the teachers' understanding of what these critical aspects entailed had deepened by the end of the study (for detail, see Mårtensson 2015). In the following section, a description is given of how the teachers enacted the set of examples in the first two lessons in the learning study. 


\section{Lesson 1}

Teacher A, who taught Lesson $1\left(\mathrm{~L}_{1}\right)$ in the learning-study cycle enacted the examples in the set one at a time, starting with the two multiplication items on the left-hand side and then followed by the two division items on the right-hand side. After that, the following four multiplication items were solved and then the four division items. In $\mathrm{L}_{1}$, none of the critical aspects were addressed through the worked set of examples, even though the set of examples was designed to address division and multiplication with numbers between $o$ and 1. One feature that was brought up by the $\mathrm{L} 1$ teacher was the inverse relationship between multiplication and division (for example, $20 \times 5=100$ and $100 \div 20=5$ ); however, this aspect was not identified by the teaching team as being critical for pupils when it came to the intended object of learning (which was why the quotient sometimes becomes bigger than the numerator). In the post-lesson meeting, the teachers realised that 'why the quotient sometimes becomes bigger than the numerator' and the critical aspects associated with this needed to be focused on more explicitly, as the variation in the set of examples does not automatically reveal the critical aspects.

\section{Lesson 2}

In Lesson 2 (L2), a revised lesson implemented in another class, Teacher B worked through the items one by one together with the pupils, starting with the examples of multiplication and then continuing with division. Afterwards, the teacher asked whether the pupils could see any patterns in or between the columns. The teacher summarised the patterns identified as 'The numbers get smaller the further down the column you go', and 'The smaller the number multiplied by is, the smaller the product and the smaller the number divided by is, the larger the quotient. The teacher pointed at $100 \div 20=5$ and $100 \div 4=25$, and said 'Here the quotient is a smaller number than the numerator; is it always like that?. In the discussion, one pupil said that after o there was a difference and another pupil said that after 1 the quotient became larger than the numerator. At this point, one of the critical aspects was brought up by means 
of the examples, namely the relationship between the numerator, denominator, and quotient. In order to make the 'turning point' explicit, the teacher drew a line under items with 1 in the denominator or one of the factors. The teacher then continued, saying that 'When the denominator is smaller than one, the quotient [points to the quotient 200 , in $100 \div 0.5=200$ ] is larger than the numerator [points to 100 , in $100 \div 0.5=200$ ]'. The teacher directed the pupils' attention to the multiplication column when he said 'What happens with the multiplication item then?' By comparing what happened in the multiplication column with the division column, it was made possible to discern that the quotient became larger than 100, and the product smaller.

After L2, the team discussed the set of examples and restricted the variation in the examples even more in L3. They changed the numbers in the examples in the multiplication and division columns (for example, $100 \times 50,100 \times 5,100 \times 1$, and $100 \times 0.5$ and $100 \times 0.1)$ in order to further direct pupils' attention towards the critical aspects, rather than calculations, by trying to ensure that the pupils were able to solve the items more easily in their heads. Thus, the examples used in the first two lessons were primarily designed and enacted to highlight the critical aspects initially identified for learning in relation to conceptual understanding of the topic taught. However, in L1, the teachers could not agree about how they should direct pupils' attention. Even though there was a pattern of variation and invariance in the task, the teacher did not address any of the critical aspects for the object of learning. However, in the post-lesson analysis of L1, the teachers agreed that the relationship between the numerator, denominator, and the quotient needed to be addressed in order to see why the quotient sometimes becomes smaller than the numerator.

\section{Final remarks-didactical consequences for teaching and learning in the classroom}

This essay reports two didactic classroom studies in which the variation of examples played a significant role. The specific aim of this essay was to illustrate how teachers used systematic variation 
in and between sets of examples in mathematics lessons. Our study contributes to knowledge about the role of sequence in the use of examples. We suggest that the enacted examples illustrated in the two studies show that what examples are used and how they are sequenced are of significance. Carefully chosen examples sequenced in a particular order can make it possible for learners to discern certain things; however, the teacher needs to direct the pupils' attention towards what the examples are intended to elucidate. We therefore agree with Rowland (2008), who suggests that single examples or randomly chosen sets of examples may impede pupils' learning (Rowland 2008; Rowland et al. 2003). Single examples, we would argue, limit pupils' opportunities to generalise from the example (Dienes 1960).

This essay highlights the use of sets of examples and what it is possible for pupils to discern from them. We have reported on two studies, and claim that the variation in and between sets of examples seems to play a significant role for learning by helping pupils to see mathematical structure and relationships. In comparison to the use of single examples, systematic variation within and between carefully chosen sets of examples, we suggest, may provide pupils with greater opportunities for learning. Hence, the variation in and between examples has subject-didactical implications in the classroom, since it illustrates what teachers can do in order to provide a more powerful learning situation for their pupils.

Lately, variation as a principle in the teaching of mathematics has gained a lot of attention, particularly in western teaching (Drury 2018; Huang 2017). The way teachers use variation in China, for example, 'one problem multiple solutions', is being used as a model by, for example, British teachers in order to accomplish better teaching and learning in the UK (Drury 2018). 'One problem multiple solutions' is variation on a larger-grained scale than the variation analysed in this essay (referred to by some researchers as procedural variation) (Drury 2018). However, variation can successfully be used in the classroom more or less systematically to a greater or lesser extent. In this essay we argue, along with others (for example, Marton 2015), 
that what is varied and how matters for learners' opportunities to discern what is intended. If teachers are not aware of what they vary or keep invariant, and why they do it, it is not likely to improve pupils' learning. Therefore, we suggest teachers need time to reflect on what variation may benefit learning in regard to the specific topic and group of learners.

In this essay, we have focused on systematic variation in regard to the examples used in two mathematics classrooms. We are aware that variation is not the only factor when teaching, since the complexity of classrooms also involves other important factors, some of which are discussed elsewhere in this volume. Nevertheless, variation as a teaching principle goes beyond the teaching and learning of mathematics, and hence can also be used in the teaching of other subjects. However, the question of which variation is the most powerful in order to enhance pupils' learning is one that needs further investigation. Systematic variation, we believe, can be used as a tool for teachers and researchers to plan and analyse lessons in order to enhance pupils' learning.

\section{Notes}

1 In this study, the term critical aspects primarily refers to the aspects that it is assumed to be necessary to discern in relation to the content and do not stem from how pupils experience the content.

2 For more details on the learning study and the learning study cycle, see Kullberg (2010).

\section{References}

Bartolini Bussi, M. G., X. Sun \& A. Ramploud (2013), 'A dialogue between cultures about task design for primary school,', in C. Margolinas (ed.), Proceedings of ICMI Study 22: Task Design in Mathematics Education (Oxford: ICMI).

Cameron, A. \& C. Fosnot (2007), New York Muffles' Truffles: Multiplication and division with the array (Portsmouth: Heinemann).

Dewey, J. (1916), Democracy and education (New York: Macmillan).

Dienes, Z. (1960), Building up mathematics (London: Hutchinson Educational). - - (1963), An experimental study of mathematics-learning (London: Hutchinson). 
Drury, H. (2018), Oxford teaching guides. How to Teach Mathematics For Mastery. Second school edition (Oxford: Oxford University Press).

Fernandez, C. \& M. Yoshida (2004), Lesson study: A Japanese approach to improving mathematics teaching and learning (Mahwah, NJ: Lawrence Erlbaum).

Gibson, J. J. \& E. J. Gibson (1955), 'Perceptual learning: Differentiation or enrichment?' Psychological Review, 62/1, 32-41.

Huang, R., Mok, I. \& Leung, F. (2006), 'Repetition or variation: Practising in the mathematics classrooms in China', in D. Clarke, C. Keitel \& Y. Shimizu (eds.), Mathematics classrooms in twelve countries: The Insider's Perspective (Rotterdam: Sense).

Huang, R., Z. Gong \& X. Han (2016), 'Implementing mathematics teaching that promotes students' understanding through theory-driven lesson study', ZDM Mathematics Education, 48/4, 425-39.

- - \& Li, Y. (2017), Teaching and learning mathematics through variation: Confucian heritage meets Western theories (Rotterdam: Sense).

Kullberg, A. (2010), What is taught and what is learned: Professional insights gained and shared by teachers of mathematics (Gothenburg: Acta Universitatis Gothoburgensis).

- - \& U. Runesson (2015), 'Examples with variation. Teachers' choice and use of mathematical examples.' Paper, presented at the European Association of Learning and Instruction biennial conference, Limassol, Cyprus, 25-29 August.

- - U. Runesson \& P. Mårtensson (2014), 'Different possibilities to learn from the same task', $P N A, 8 / 4,139-50$.

Lewis, C., R. Perry \& J. Hurd (2009), 'Improving mathematics instruction through lesson study: A theoretical model and North American case', Journal of Mathematics Teacher Education, 12/4, 285-304.

Marton, F. (1981), 'Phenomenography-Describing conceptions of the world around us', Instructional Science, 10/2, 177-200.

_- \& S. Booth (1997), Learning and awareness (Mahwah, NJ: Lawrence Erlbaum).

- - \& M. F. Pang (2006), 'On some necessary conditions of learning', Journal of the Learning Sciences, 15/2, 193-220.

Marton, F. (2015), Necessary conditions of learning (New York: Routledge).

Mason, J. \& D. Pimm (1984), 'Generic examples: Seeing the general in the particular', Educational Studies in Mathematics, 15/3, 227-89.

Mårtensson, P. (2015), Att få syn på avgörande skillnader: Lärares kunskap om lärandeobjektet (Jönköping: School of Education and Communication, Jönköping University).

Rowland, T. (2008), 'The purpose, design and use of examples in the teaching of elementary mathematics', Educational Studies in Mathematics, 69/2, 149-63.

Rowland, T., A. Thwaites \& P. Huckstep (2003), 'Novices' choice of examples in 
the teaching of elementary mathematics', paper presented at the Mathematics Education into the 21st Century Project, at the conference The Decidable and the Undecidable in Mathematics Education, Brno, Czech Republic, 19-25 Sept. Simon, M. A. \& R. Tzur (2004), 'Explicating the role of mathematical tasks in conceptual learning: An elaboration of the hypothetical learning trajectory', Mathematical Thinking and Learning, 6/2, 91-104.

Skodras, C. (2015), Undervisning i multiplikation genom systematiskt varierade exempel (magisteruppsats/BA dissertation) [Teaching multiplication through systematic variation of examples]. (Gothenburg: Göteborgs universitet).

Sun, X. (2011), "Variation problems" and their roles in the topic of fraction division in Chinese mathematics textbook examples', Educational Studies in Mathematics, 76/1, 65-85.

Vamvakoussi, X. \& S. Vosniadou (2004), 'Understanding the structure of the set of rational numbers: A conceptual change approach', Learning \& Instruction, 14, 453-67.

Verschaffel, L., B. Greer \& E. De Corte (2007), 'Whole number concepts and operations', in F. K. J. Lester (ed.), Second handbook of research on mathematics teaching and learning, ii (Charlotte, NC: Information Age).

Watson, A. \& J. Mason (2002), 'Student-generated examples in the learning of mathematics', Canadian Journal of Science, Mathematics \& Technology Education, 2/2, 237-49.

Watson, A. \& J. Mason (2006), 'Seeing an exercise as a single mathematical object: Using variation to structure sense-making', Mathematical Thinking \& Learning, 8/2, 91-111.

Wertheimer, M. (1945), Productive thinking (New York: Harper).

Zazkis, R. \& E. J. Chernoff (2008), 'What makes a counter example exemplary?' Educational Studies in Mathematics, 68(3), 195-208.

Zodik, I. \& O. Zaslavsky (2008), 'Characteristics of teachers' choice of examples in and for mathematics', Educational Studies in Mathematics, 69/2, 165-82. 